\title{
O Criador, a criatura e a criação: para uma primeira leitura teológica
}

Eva Aparecida Rezende de Moraes $^{1}$

Começamos com uma pergunta: qual a relevância hoje do tema "Deus Criador"? O próprio Papa Francisco, em sua Encíclica Laudato si (LS), reconhece essa inquietação ${ }^{2}$. Ele não ignora que alguns, principalmente no campo da política e do pensamento, rejeitam a ideia de um Criador ou consideram-na irrelevante (LS, n. 62). Mas ele destaca, em seu texto, a riqueza que as religiões podem oferecer para a construção de uma ecologia integral e para o pleno desenvolvimento do gênero humano. O Papa afirma que a ciência e a religião, mesmo fornecendo diferentes abordagens da realidade, podem entrar num diálogo intenso e frutuoso para ambas. Ele não ignora que, para transformar a realidade, é necessário, também, recorrer às diversas riquezas culturais dos povos, à arte, à poesia e à espiritualidade - nenhum ramo das ciências e nenhuma forma de sabedoria podem ser esquecidos. Afirma que a Igreja Católica está aberta ao diálogo com o pensamento filosófico, produzindo sínteses entre fé e razão - inclusive nas questões sociais, como bem mostra a Doutrina Social da Igreja (LS, n. 63). Outro motivo importante, segundo o Papa Francisco, para uma contribuição teológica nesse assunto é o fato de que as convicções da fé cristã oferecem aos católicos e, em parte, também a outros crentes, motivações altas para cuidar da natureza e dos irmãos e irmãs mais frágeis (LS, n. 64).

Inicialmente, ao tratarmos de um Criador, nos defrontamos com os desafios ecológicos dos dias de hoje. Como se sabe, houve grande crescimento, em todo o mundo especialmente da década de 70 para cá -, de conferências, simpósios e congressos, com objetivos claros de se pensar políticas públicas, nacionais e internacionais, voltadas, majoritariamente, para a preservação do meio ambiente. A Organização das Nações Unidas (ONU), juntamente com a Organização Metereológica Mundial (OMM) criaram, em 1988, o chamado Painel Intergovernamental sobre as Alterações Climáticas (IPCC), que tem fornecido diversas informações científicas, técnicas e socioeconômicas de forma relevante e neutra, possibilitando, aos gestores públicos, muitos auxílios na formatação e criação de leis ambientais. Atualmente, o nosso maior problema ou desafio é, sobretudo, de caráter decididamente filosófico, segundo o autor Leonardo Boff (1996, p. 52): o maior desafio hoje, é tentar estabelecer, no ser humano, uma consciência ecológica.

Diante desse desafio - conciliar as pesquisas científicas e o olhar teológico cristão -, a Igreja Católica tem se posicionado em vários Documentos. Um bastante interessante é a Encíclica Fides et ratio (Fé e razão), do Papa João Paulo II, de 14 de setembro de 1998. O

\footnotetext{
${ }_{2}^{1}$ Física e Teóloga, professora do Setor de Cultura Religiosa da PUC-Rio Cf. PAPA FRANCISCO. Encíclica http://w2.vatican.va/content/francesco/pt/encyclicals/documents/papa-francesco_20150524_enciclica-laudatosi.html
} 
Documento abre, dizendo que: "A fé e a razão (fides et ratio) constituem como que as duas asas pelas quais o espírito humano se eleva para a contemplação da verdade". A busca da verdade marca o ser humano - e não somente nos escritos judaico-cristãos, como nos diz esse Documento acima:

(...) Basta um simples olhar pela história antiga para ver com toda a clareza como surgiram, simultaneamente, em diversas partes da terra, animadas por culturas diferentes, as questões fundamentais que caracterizam o percurso da existência humana: Quem sou eu? Donde venho e para onde vou? Porque existe o mal? O que é que existirá depois desta vida? Estas perguntas encontram-se nos escritos sagrados de Israel, mas aparecem, também, nos Vedas e no Avestá; achamo-las tanto nos escritos de Confúcio e Lao-Tze, como na pregação de Tirtankara e de Buda; e assomam, ainda, quer nos poemas de Homero e nas tragédias de Eurípides e Sófocles, quer nos tratados filosóficos de Platão e Aristóteles. São questões que têm a sua fonte comum naquela exigência de sentido que, desde sempre, urge no coração do homem: da resposta a tais perguntas depende, efetivamente, a orientação que se imprime à existência (n. 1).

Neste e em outros Documentos, a Igreja reconhece que

(...) uma razão cheia de interrogativos levou por diante o seu desejo de conhecer sempre mais ampla e profundamente. Desta forma, foram construídos sistemas de pensamento complexos, que deram os seus frutos nos diversos âmbitos do conhecimento, favorecendo o progresso da cultura e da história. A antropologia, a lógica, as ciências da natureza, a história, a linguística, de algum modo todo o universo do saber foi abarcado (...) (n. 5).

O Documento, ainda, nos diz que esta ligação vem desde as Sagradas Escrituras:

Quão profunda seja a ligação entre o conhecimento da fé e o da razão, já a Sagrada Escritura no-lo indica com elementos de uma clareza surpreendente. (...) Não é por acaso que o autor sagrado, ao querer descrever o homem sábio, o apresenta como aquele que ama e busca a verdade: 'Feliz o homem que é constante na sabedoria, e que discorre com a sua inteligência; que repassa no seu coração os caminhos da sabedoria, e que penetra no conhecimento dos seus segredos...' (Sir 14, 20-27)". (n. 16)

Assim,

(...) o caráter peculiar do texto bíblico reside na convicção de que existe uma unidade profunda e indivisível entre o conhecimento da razão e o da fé. $O$ mundo e o que nele acontece, assim como a história e as diversas vicissitudes da nação, são realidades observadas, analisadas e julgadas com os meios próprios da razão, mas sem deixar a fé alheia a este processo...

E mais:

Não há motivo para existir concorrência entre a razão e a fé: uma implica a outra, e cada qual tem o seu espaço próprio de realização. Aponta nesta 
direção o livro dos Provérbios, quando exclama: 'A glória de Deus é encobrir as coisas, e a glória dos reis é investigá-las' $(25,2)$.

Outro Documento que também nos ajuda na questão atual dos desafios do ecossistema é de 1991, do Papa João Paulo II: a Encíclica Centesimus annus, onde lemos, no n. 55: "A dimensão teológica revela-se necessária para interpretar e resolver os problemas atuais da convivência humana". Tem sido feito um esforço intelectual, entre os teólogos, de fundamentar uma teologia com esse foco: a ecoteologia está voltada para o desenvolvimento de uma postura cristã, onde, o que predomina, são tentativas de revigorar e fortalecer uma atitude ética e moral, preocupada com a preservação e o futuro do planeta. Esse pequeno artigo é uma tentativa de dizer uma palavra teológica, mesmo que superficialmente, a esse respeito.

Um dos valores éticos mais profundos e mais identificadores da humanidade é a liberdade. Segundo a Tradição cristã, a liberdade humana é marcada por múltiplas relações: com o cosmos (= natureza), com os outros (= sociedade) e com o Transcendente (= Deus) ${ }^{3}$. Alguns teólogos recentes - como, por exemplo, Garcia Rúbio (1989), Antonio Moser (1992) e Josafá Siqueira (1998) - procuram fundamentar que a crise ecológica que vivemos desde a Modernidade, está ligada, profundamente, a uma crise do próprio ser humano e da sociedade como um todo. A cultura da modernidade foi marcada por um antropocentrismo (ética tendo como centro o ser humano) arrogante, egoísta e individualista, que entendeu o ser humano como senhor absoluto da natureza, dispondo dela de maneira meramente mecanicista e depredatória, visando, muitas vezes, apenas à produtividade e ao lucro que ela proporciona. Esta marca cultural ignora a presença de Deus na natureza: sem um Criador e sem um objetivo maior para ser criada, a natureza deixa de ser Criação, sendo, apenas, um mero fruto do acaso e algo para ser "consumido". Portanto, para esses e outros autores, essa crise ecológica se tornou, também, uma crise antropológica, porque quebrou uma relação, antes criada inseparavelmente segundo a fé judaico-cristã, entre ser humano e natureza. Na Modernidade, o ser humano não se sentiu mais parte da natureza, mas dono dela. Essa crise ecoantropológica provocou uma desarticulação e uma desintegração entre as diversas expressões da pluralidade da liberdade humana. Segundo, por exemplo, Garcia Rúbio, o papel da teologia é mostrar a relação íntima existente entre ser humano, cosmo criado e Criador. Por sua vez, não é de estranhamento dos teólogos, uma crítica que alguns autores têm feito ao Livro Sagrado de judeus e cristãos, no Livro do Gênesis, que trata da Criação, por Deus, do cosmos e do ser humano, no Capítulo 1,26-28:

\footnotetext{
${ }^{3}$ Cf. SIQUEIRA, Josafá Carlos de, S.J. Ética e meio ambiente. Rio de Janeiro: Loyola. 1998. P. 35.
} 
Depois, Deus disse: «Façamos o ser humano à nossa imagem, à nossa semelhança, para que domine sobre os peixes do mar, sobre as aves do céu, sobre os animais domésticos e sobre todos os répteis que rastejam pela terra.» Deus criou o ser humano à sua imagem, criou-o à imagem de Deus; Ele os criou homem e mulher. Abençoando-os, Deus disse-lhes: "Crescei e multiplicai-vos, enchei e dominai a terra. Dominai sobre os peixes do mar, sobre as aves dos céus e sobre todos os animais que se movem na terra".

Elias Gomes da Silva é um dos autores que nos revelam essa crítica feita nas últimas décadas a essa passagem do texto bíblico: o mandato divino ao ser humano de "dominar" a terra ${ }^{4}$. Segundo os críticos, este teria sido um dos motivos da enorme depredação feita ao planeta, especialmente no século XX. Houve críticas elaboradas nas décadas de 60 e 70 nos Estados Unidos, sobretudo por alguns ambientalistas - dentre os quais, se destacou Lynn White Branco Jr. (1908-1988). Essas críticas foram respondidas pela comunidade teológica ao longo desses anos, culminando na criação de uma teologia eminentemente preocupada em estabelecer uma releitura de textos canônicos, a partir de uma hermenêutica profundamente de caráter ecológico (REIMER, 2008, p. 85). O Papa Francisco, em sua Encíclica Laudato si, afirma que essa não é uma interpretação correta da Bíblia, como a entende a Igreja: se é verdade que nós, cristãos, algumas vezes interpretamos incorretamente as Escrituras, hoje devemos rejeitar que, do fato de sermos criados à imagem de Deus e do mandato de "dominar a terra", se deduza um domínio absoluto sobre as outras criaturas - segundo o Papa nessa Encíclica, é importante ler os textos bíblicos no seu contexto (n. 67).

Sem aprofundarmos no método de análise escriturística, autores como Josafá Siqueira fundamentam que, no Livro acima citado, no conjunto da narrativa, existe uma unidade criacional - ou seja: Deus criou todas as coisas de maneira integrada. A criação do cosmos está relacionada com a criação do ser humano ${ }^{5}$. Percebe-se, no relato, que Deus tem um mesmo olhar sobre todas as criaturas: um olhar de amor e bondade. Assim vemos, em várias partes do Capítulo 1:

${ }^{10}$ Deus chamou terra à parte sólida, e mar, ao conjunto das águas. $\boldsymbol{E}$ Deus viu que isto era bom. (...) ${ }^{12}$ A terra produziu verdura, erva com semente, segundo a sua espécie, e árvores de fruto, segundo as suas espécies, com a respectiva semente. Deus viu que isto era bom. (...) ${ }^{17}$ Deus colocou-os no firmamento dos céus para iluminarem a Terra, ${ }^{18}$ para presidirem ao dia e à noite, e para separarem a luz das trevas. E Deus viu que isto era bom. (...) ${ }^{21}$ Deus criou, segundo as suas espécies, os monstros marinhos e todos os seres vivos que se movem nas águas, e todas as aves aladas, segundo as

\footnotetext{
${ }^{4}$ SILVA, Elias Gomes da. "Religiosidade e Meio Ambiente: das Críticas dos Ambientalistas à Construção de uma Ecoteologia" (Religion and the Environment: The Environmental Criticism of Building a the Ecotheology). In: http://revistas.pucsp.br/index.php/reveleteo - Revista Eletrônica Espaço Teológico ISSN 2177-952x vol. 4, n.6, jun/dez, 2010, pp. 132-140.

${ }^{5}$ Cf. SIQUEIRA, Josafá Carlos de, op. cit., p. 35.
} 
suas espécies. E Deus viu que isto era bom. (...) ${ }^{25}$ Deus fez os animais ferozes, segundo as suas espécies, os animais domésticos, segundo as suas espécies, e todos os répteis da terra, segundo as suas espécies. $\boldsymbol{E}$ Deus viu que isto era bom. (...) ${ }^{26}$ Depois, Deus disse: «Façamos o ser humano à nossa imagem, à nossa semelhança, para que domine sobre os peixes do mar, sobre as aves do céu, sobre os animais domésticos e sobre todos os répteis que rastejam pela terra». (...) ${ }^{27}$ Deus criou o ser humano à sua imagem, criou-o à imagem de Deus; Ele os criou homem e mulher. (...) ${ }^{31}$ Deus, vendo toda a sua obra, considerou-a muito boa.

Como podemos ver acima, o juízo ético judaico-cristão sobre a natureza e o ser humano é positivo, resguardando a bondade que existe no todo criado - uma bondade que procede do seu Criador, que é sumamente Bom. Podemos observar que, após a criação do ser humano - homem e mulher - pelo Criador, Ele observou, ao contemplar toda a Sua obra, que ela é muito boa! Essa bondade que procede do Criador está presente, portanto, em toda a Criação. Dentro desse conjunto de análises, podemos, então, concluir que o mandato de "dominar" a terra deve vir entre aspas - ou seja: se é um domínio, deverá ser um domínio amoroso e cuidador! Isto aparece claramente no Capítulo 2 do mesmo Livro (Gênesis), versículo 15, onde temos, concretamente, a vocação primeira do ser humano, criado por Deus: "O Senhor Deus levou o homem e colocou-o no jardim do Éden, para o cultivar e também para o guardar". O Papa Francisco, em sua Encíclica Laudato si, nos recorda que "cultivar" quer dizer lavrar ou trabalhar um terreno e, "guardar", significa proteger, cuidar, preservar, velar - o que implica uma relação de reciprocidade responsável entre ser humano e natureza (n. 67).

Como entender esses dois relatos assim distintos no mesmo Livro do Gênesis, em se tratando da Criação de Deus? Garcia Rubio (1989) fundamenta que, na Bíblia, aparecem duas tradições interpretativas: a primeira ("dominai a terra”) é mais antropocêntrica, onde o ser humano se destaca da natureza; na segunda ("cultivar e guardar"), a perspectiva é mais cosmocêntrica, sublinhando a participação do ser humano no $\operatorname{cosmos}^{6}$. Esta última tradição, que ressalta mais a unidade entre ser humano e cosmos, está presente em outras partes do texto bíblico, como, por exemplo: "Vós, Senhor, quereis salvar o homem e os animais" (Salmo 36,7); "O justo florescerá como uma palmeira, crescerá como cedro do Líbano; plantados na casa do Senhor, nos átrios de nosso Deus hão de florir. Ainda na velhice, darão frutos cheios de seiva e verdejantes, para proclamar que o Senhor é justo, que em Deus não existe qualquer mal!" (Salmo 92,13-16); "Ele deu uma ordem e tudo foi criado; Ele fixou tudo pelos séculos sem fim e estabeleceu leis a que não se pode fugir!' (Salmo 148, 5b-6); "Se vires o jumento do teu irmão ou o seu boi caídos no caminho, não te desvies deles, mas ajuda-os a levantarem-se. (...) Se encontrares no caminho, em cima de uma

\footnotetext{
${ }^{6}$ Cf. ibidem, p. 36-37.
} 
árvore ou no chão, um ninho de pássaros com filhotes, ou ovos cobertos pela mãe, não apanharás a mãe com a ninhada" (Deuteronômio 22, 4.6); o descanso do sétimo dia não é proposto só para o ser humano, mas "...para que descansem o teu boi e o teu jumento" (Êxodo 23, 12). Assim, vemos que a bondade do Criador está presente em toda a Sua Criação.

Segundo o n. 20 do Compêndio da Doutrina Social da $\operatorname{lgreja}^{7}$, toda autêntica experiência religiosa, em todas as tradições culturais, conduz a uma intuição do Mistério de Deus: Ele aparece, por um lado, como origem daquilo que é, como presença que garante aos homens, socialmente organizados, as condições básicas de vida, pondo à disposição os bens necessários; e, por outro lado, como medida do que deve ser, como presença que interpela o agir humano - no plano pessoal e no social - sobre o uso dos mesmos bens nas relações com os outros homens. Em toda experiência religiosa, portanto, se revelam importantes: (i) a dimensão do dom e da gratuidade, subjacente à experiência que a pessoa humana faz do seu existir junto com os outros no mundo; e (ii) as repercussões desta dimensão sobre a consciência do homem, que é interpelado a gerir de forma responsável e convival o dom recebido. Esta é a regra de ouro, em que se exprime, no plano das relações, a lei inscrita por Deus no ser humano: "Tudo o que quereis que os homens vos façam, fazeio vós a eles". Ainda no Compêndio, vemos o princípio da criação de todas as coisas por parte de Deus: afirmar que Deus é Criador significa perceber o horizonte originário do agir gratuito e misericordioso do Senhor em favor do ser humano - o homem e a mulher, criados à Sua imagem e semelhança (cf. Gn 1, 26-27), são, por isso mesmo, chamados a ser o sinal visível e o instrumento eficaz da gratuidade divina no jardim em que Deus os pôs como cultivadores e guardiões (n. 26). O sentido profundo da Criação vem expresso pelo agir gratuito de Deus Criador - ainda que obscurecido e distorcido pela experiência do pecado dos nossos primeiros pais (cf. Gn 3, 1-24): desobedecer a Deus significa furtar-se ao seu olhar de amor e querer administrar por conta própria o mundo. A ruptura da relação de comunhão com Deus provoca também ruptura: da unidade interior da pessoa humana, da comunhão entre o homem e a mulher e da harmonia entre os humanos e não humanos ( $\mathrm{n}$. 27).

O Compêndio ainda nos recorda que as páginas do primeiro livro da Sagrada Escritura, que descrevem a criação do homem e da mulher à imagem e semelhança de Deus (cf. Gn 1, 26-27), encerram um ensinamento fundamental sobre a identidade e a vocação da pessoa humana: (i) a criação do homem e da mulher é um ato livre e gratuito de Deus; (ii) o homem e a mulher, porque livres e inteligentes, constituem o tu criado de Deus

\footnotetext{
${ }^{7} \mathrm{Cf}$. http://www.vatican.va/roman_curia/pontifical_councils/justpeace/documents/rc_pc_justpeace_doc_20060526_co mpendio-dott-soc_po.html.
} 
e, por isto, somente na relação com Ele podem descobrir e realizar o significado autêntico e pleno de sua vida pessoal e social; (iii) o homem e a mulher são a imagem do Amor Trinitário no universo criado; (iv) ambos são o ápice da criação e o Criador Ihes confia a tarefa de ordenar a natureza criada - mas segundo o desígnio do seu Criador (cf. Gn 1, 28) (n. 36). O livro do Gênesis nos propõe algumas linhas mestras da antropologia cristã: (i) a inalienável dignidade da pessoa humana, porque criado por Deus; (ii) a sociabilidade constitutiva do ser humano, que tem o seu protótipo na relação originária entre o homem e a mulher - primeira expressão da comunhão de pessoas; (iii) o agir humano no mundo deve ser ligado à descoberta e ao respeito da lei natural que Deus imprimiu no universo criado, onde a humanidade deve habitar e guardar, segundo o projeto do Criador (cf. 2Pd 3, 13).

Também em sua Encíclica Laudato si, o Papa Francisco afirma que a responsabilidade humana perante a Criação e o Criador implica que o ser humano, dotado de inteligência, respeite as leis da natureza e os delicados equilíbrios entre os seres deste mundo (n. 68). Podemos fazer um uso responsável das coisas e reconhecer que os outros seres vivos têm um valor próprio diante de Deus, "pelo simples fato de existirem"; por ser dotado de inteligência, o ser humano é chamado a respeitar a criação com as suas leis internas (n. 69). Hoje, a Igreja não diz, de forma simplista, que as outras criaturas estão totalmente subordinadas ao bem do ser humano, mas ensina, em seu Catecismo ${ }^{8}$, no n. 339:

Cada criatura possui a sua bondade e perfeição próprias. (...) As diferentes criaturas, queridas pelo seu próprio ser, refletem, cada qual a seu modo, uma centelha da sabedoria e da bondade infinitas de Deus. É por isso que o homem deve respeitar a bondade própria de cada criatura, para evitar o uso desordenado das coisas.

Encerramos, assim, esse breve texto, nos perguntando: quais seriam, enfim, os princípios teológicos que devem estar presentes na construção de uma ética ambiental? Quem nos ajuda a responder é Pe. Josafá Siqueira 9 . Segundo este autor, seriam eles:

(i) A bondade - olhar a natureza com bondade significa reconhecer a presença amorosa de Deus em tudo e em todos. Com esse olhar, contemplamos a natureza - o que não significa um sentimento romântico, mas uma atitude teológica, que percebe que cada criatura, cada diferença neste pluriverso mundo da natureza, é reflexo e espelho da presença do Criador. Para isso, precisamos desenvolver uma sensibilidade para os detalhes de cada ser criado: as diferenças, as singularidades,... Somente através desta sensibilidade é que podemos entender a bondade divina que se manifesta na Criação.

\footnotetext{
${ }^{8}$ CATECISMO DA IGREJA CATÓLICA. In: http://www.vatican.va/archive/ccc/index_po.htm .

${ }^{9}$ Cf. SIQUEIRA, Josafá Carlos de, op. cit., p. 39-40.
} 
(ii) A solidariedade - reconhecer que os seres criados estão em íntima relação, e não apenas devido às cadeias biológicas ou ecossistêmicas: na multiplicidade existencial, todos os seres criados estão em conexão solidária com o Criador. Essa solidariedade teológica só é compreendida numa visão de fé, e só pode ser buscada na "harmonia dos contrários" inerente a cada ser criado: como afirma Antonio Moser (1992), todas as formas de vida revelam, ao mesmo tempo, força e fraqueza, grandeza e pequenez, beleza e rusticidade, mansidão e selvageria. Todas as formas de vida são contrastes numa sinfonia harmônica. $O$ ser humano que destrói o meio ambiente é um ser surdo (não ouvir essa sinfonia) e não solidário (destruir é quebrar a harmonia).

(iii) A salvação integral - esta é uma afirmação da fé judaico-cristã: o ser humano e a natureza são salvos ao mesmo tempo. Ao longo da Bíblia, encontramos vários textos que tratam dessa unidade íntima entre o ser humano e a natureza, como, por exemplo, no Livro do Gênesis, Capítulo 9, versículos 8 a 17:

\begin{abstract}
Então disse Deus a Noé e a seus filhos, que estavam com ele: 'Vou estabelecer a minha aliança com vocês e com os seus futuros descendentes, e com todo ser vivo que está com vocês: as aves, os rebanhos domésticos e os animais selvagens, todos os que saíram da arca com vocês, todos os seres vivos da terra. Estabeleço uma aliança com vocês: nunca mais será ceifada nenhuma forma de vida pelas águas de um dilúvio; nunca mais haverá dilúvio para destruir a terra'. E Deus prosseguiu: 'Este é o sinal da aliança que estou fazendo entre mim e vocês e com todos os seres vivos que estão com vocês, para todas as gerações futuras: o meu arco que coloquei nas nuvens. Será o sinal da minha aliança com a terra. Quando eu trouxer nuvens sobre a terra e nelas aparecer o arco-íris, então me lembrarei da minha aliança com vocês e com os seres vivos de todas as espécies. Nunca mais as águas se tornarão um dilúvio para destruir toda forma de vida. Toda vez que o arco-íris estiver nas nuvens, olharei para ele e me lembrarei da aliança eterna entre Deus e todos os seres vivos de todas as espécies que vivem na terra'. Concluindo, disse Deus a Noé: 'Esse é o sinal da aliança que estabeleci entre mim e toda forma de vida que há sobre a terra'.
\end{abstract}

Também, no Salmo 36,7: "Como é precioso o teu amor, ó Deus! Os homens encontram refúgio à sombra das Tuas asas!"; ou, como escreve Paulo de Tarso aos Romanos:

Considero que os nossos sofrimentos atuais não podem ser comparados com a glória que em nós será revelada. A natureza criada aguarda, com grande expectativa, que os filhos de Deus sejam revelados. Pois ela foi submetida à futilidade, não pela sua própria escolha, mas por causa da vontade daquele que a sujeitou, na esperança de que a própria natureza criada será libertada da escravidão da decadência em que se encontra para a gloriosa liberdade dos filhos de Deus. Sabemos que toda a natureza criada geme até agora, como em dores de parto. E não só isso, mas nós mesmos, que temos os 
primeiros frutos do Espírito, gememos interiormente, esperando ansiosamente nossa adoção como filhos, a redenção do nosso corpo $(\mathrm{Rm}$ 8,18-23).

Especialmente na Bíblia cristã, o destino último da Criação é vivenciar, plenamente, aquela bondade inerente à mesma, desde o ato criador de Deus. Os cristãos leem, no último Livro da Bíblia - o Apocalipse -, no Capítulo 21, versículos 4 a 7:

E Deus limpará de seus olhos toda a lágrima; e não haverá mais morte, nem pranto, nem clamor, nem dor; porque já as primeiras coisas são passadas. E o que estava assentado sobre o trono disse: 'Eis que faço novas todas as coisas'. E disse-me: 'Escreve; porque estas palavras são verdadeiras e fiéis'. E disse-me mais: 'Está cumprido. Eu sou o Alfa e o Ômega, o princípio e o fim. A quem quer que tiver sede, de graça lhe darei da fonte da água da vida. Quem vencer, herdará todas as coisas; e eu serei seu Deus, e ele será meu filho'.

A Bíblia Sagrada abre, no primeiro Livro - o Gênesis -, com uma palavra positiva acerca da Criação - que criou tudo por Amor e Bondade - e encerra, no último Livro - o Apocalipse - com uma palavra de otimismo sobre a humanidade, o mundo, enfim, a Criação!

\section{REFERÊNCIAS BIBLIOGRÁFICAS:}

CATECISMO DA IGREJA CATÓLICA. In: http://www.vatican.va/archive/ccc/index_po.htm

PAPA FRANCISCO. Encíclica Laudato si. http://w2.vatican.va/content/francesco/pt/encyclicals/documents/papafrancesco_20150524_enciclica-laudato-si.html

SILVA, Elias Gomes da. "Religiosidade e Meio Ambiente: das Críticas dos Ambientalistas à Construção de uma Ecoteologia" (Religion and the Environment: The Environmental Criticism of Building a the Ecotheology). In: http://revistas.pucsp.br/index.php/reveleteo Revista Eletrônica Espaço Teológico ISSN 2177-952x vol. 4, n.6, jun/dez, 2010

SIQUEIRA, Josafá Carlos de, S.J. Ética e meio ambiente. Rio de Janeiro: Loyola. 1998 